\title{
Research on Reduction of Solar Power Curtailment with Grid Connected Energy Storage System Based on Time-Series Production Simulation
}

\author{
S. Ma1, Y. P. Xu' ${ }^{1}$, X. F. Li' ${ }^{1}$, Y. F. Wang', N. Zhang1, Y. R. Xu' \\ ${ }^{1}$ State Key Laboratory of Operation and Control of Renewable Energy \& Storage Systems, China Electric Power Research Institute. \\ Beijing, China \\ ${ }^{2}$ Qinghai Electric Power Dispatch and Control Centre, Qinghai, China \\ Email: mashuo@epri.sgcc.com.cn
}

How to cite this paper: Ma, S., Xu, Y.P., Li, X.F., Wang, Y.F., Zhang, N. and Xu, Y.R. (2017) Research on Reduction of Solar Power Curtailment with Grid Connected Energy Storage System Based on Time-Series Production Simulation. Energy and Power Engineering, 9, 162-175.

https://doi.org/10.4236/epe.2017.94B020

Received: February 3, 2017

Accepted: March 30, 2017

Published: April 6, 2017

\begin{abstract}
Due to the variable output of renewable energy (RE) generation, difficulties of dispatching RE for power system operators could not be avoided. One of possible solutions is the energy storage technology, especially the battery storage system. The large-scale energy storage system is available to support power system reliable flexibility for load following and system frequency regulation. In this paper, the bottlenecks of large-scale solar power generation dispatching and operation in Qinghai grid are discussed, and a new PVenergy storage coordinated dispatching method is proposed for reduction of PV curtailment in Qinghai. Moreover, the validation based on the time-series production simulation is provided using real data from Qinghai. The results indicate that the proposed method can effectively decrease the curtailment of solar power and future vision of large-scale solar power coordinated operation with energy storage system is also presented.
\end{abstract}

\section{Keywords}

Solar power, curtailment, energy storage, time-series production simulation

\section{Introduction}

The large-scale power bases of wind and PV contributed to over $80 \%$ of the total grid connected renewable energy (RE) in China, which is one of the distinct differences of RE development between China and other countries. With the concentrated construction of large-scale PV power station and insufficient system flexibility and power transmission capacity, there has been PV curtailment in 
Qinghai in recent years. In a non-market system, the common dispatching strategy usually focuses on conventional units and has no (or limited) coordinated consideration of renewable generation with energy storage system. However, with large-scale RE integration, this has resulted in a significant limitation of RE utilization and the RE consumption capability of the system is difficult to be maximum. Several papers have discussed the power system operation with RE integration and operation, including long-term planning [1] [2], multi-source generation optimal dispatching [3], system accommodation capability evaluation [4] [5], energy storage with RE [6] [7], optimal dispatching and scheduling [8], coordinated dispatching and control [9], and RE curtailment [10] [11].

However, most researches did not consider multi-energy storage comparison such as heat storage or large-scale pumped storage station coordinated operation with RE. In addition, with the decrease of cost of energy storage technologies recently, the feasibility and economy of energy storage is becoming available for system operator to deal with RE curtailment. This paper discusses the bottlenecks of PV operation with the conventional dispatching strategy in a typical provincial power grid of China. Based on the flexibility of energy storage system, from the complementary and coordinated angle of PV and energy storage system, a PV-storage optimal dispatching strategy is proposed. Validation is presented by actual operation data from the Qinghai grid based on the time-series production simulation. Besides, other forms of energy storage system such as solar power with heat storage and large-scale PV operation with pumped storage are also discussed.

\section{Current Status of Solar Pv Power Operation in Qinghai}

By the end of first half of 2016, the installed RE capacity was 7370 MW (Solar power is $6784 \mathrm{MW}$ ), accounting for $32.4 \%$ of gross installed capacity. PV electricity was 4.4 TWh and 0.6 TWh was curtailed, accounting for $12 \%$ of theoretical PV generation according to NEA's data. And as the heating period comes at the end of year, the curtailment will be worse.

\subsection{Load Characteristics}

The maximum load of Qinghai grid in 2015 was 9160 MW, and electricity demand was 71.7 TWh. The daily load curves in 2015 are given below in Figure 1. It is shown that load variation is not very big, thus it seems more "flat" and the load difference between peak and valley is quite small.

\subsection{Characteristics of PV Generation Operation}

The daily curves of PV output in Qinghai are shown in Figure 2. The $\mathrm{X}$ axis is 24 hours of a day, $\mathrm{Y}$ axis is 365 days of a year and $\mathrm{Z}$ axis presents the ratio between PV output and its capacity. It is clear that Qinghai province is rich in solar resource and most of days in 2015 are fine day with excellent solar radiation, except some cloudy and rainy days in summer time (June to August) that maximum PV output was basically less than $50 \%$ of capacity. 


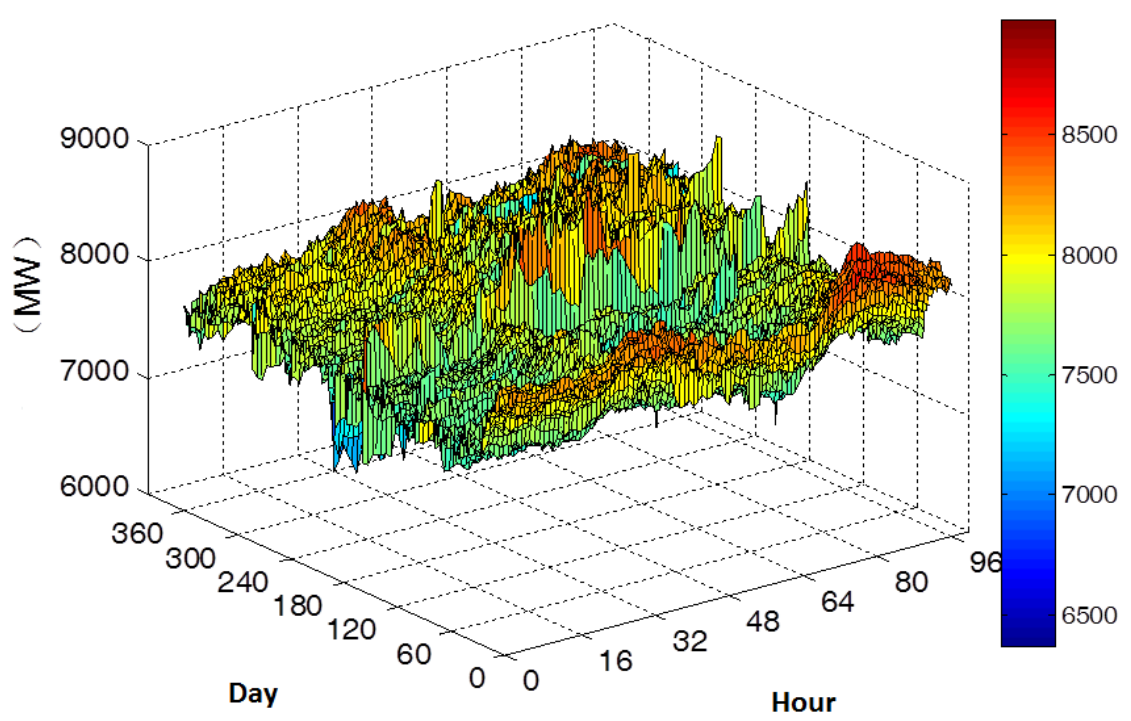

Figure 1. Daily load curves of Qinghai grid in 2015.

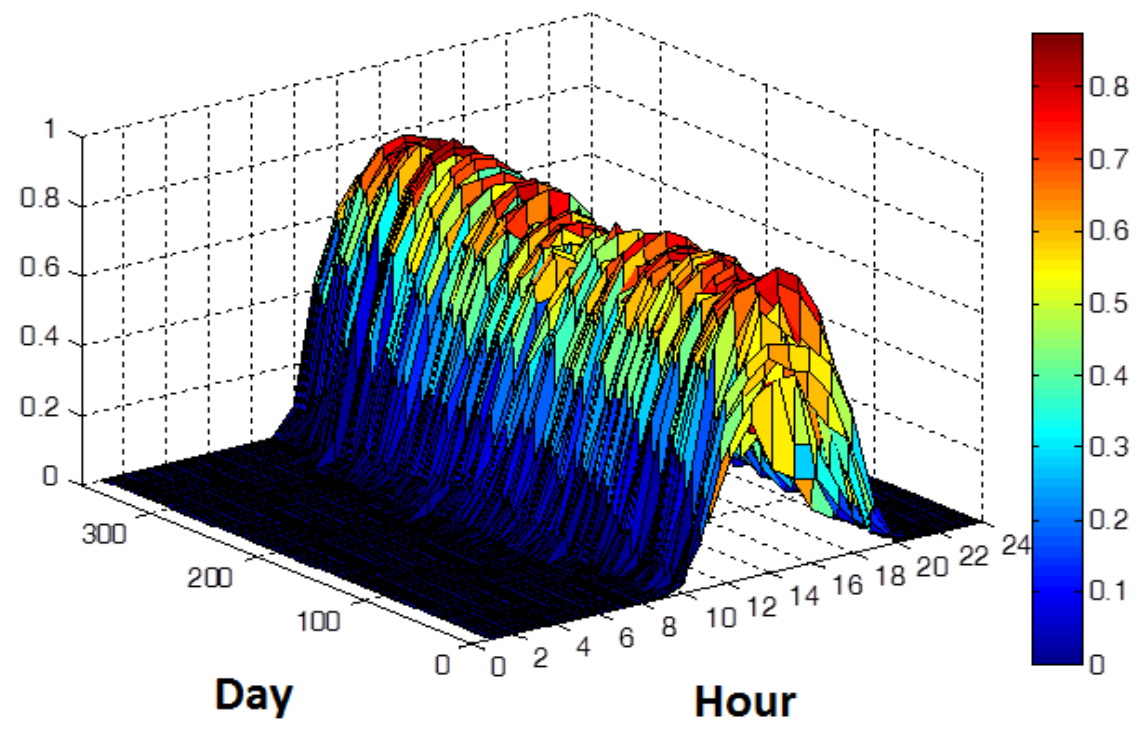

Figure 2. Daily PV output curves of Qinghai grid.

The probability distribution and cumulated probability distribution of maximum PV output variation within $15 \mathrm{~min}$ are shown in Figure 3. It can be found that when the time resolution is within $15 \mathrm{~min}$, the PV power variation mainly distributed in the interval from $-10 \%-10 \%$ of capacity and, the probability is nearly $98 \%$. Furthermore, the probability of interval from $-3 \%-3 \%$ is over $78 \%$.

\subsection{The Bottlenecks of PV Power Operation and Curtailment}

\subsubsection{Weak Consumption}

Due to slow growth of economy and electricity demand of Qinghai, the total consumption ability of RE is significantly weak. Currently, the average load of Qinghai grid is $6800 \mathrm{MW}$, and it is just equal to the level of the end of 2012. However, as described previously, the solar power installed capacity is already 


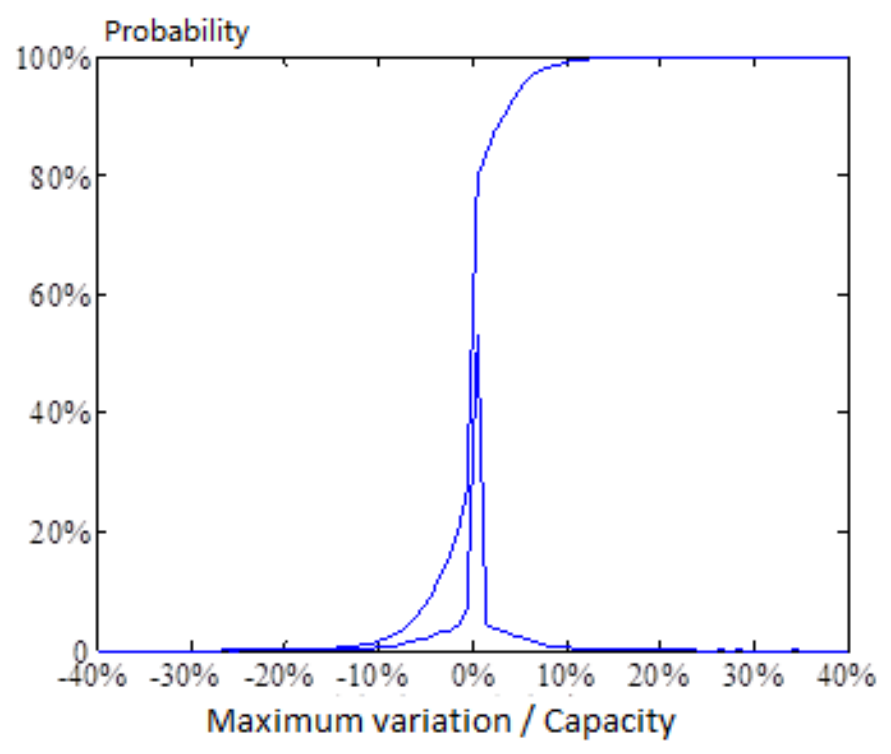

Figure 3. Probability distribution and cumulated probability distribution of maximum PV variation within $15 \mathrm{~min}$.

$6784 \mathrm{MW}$, and basically the maximum acceptable PV power of Qinghai grid is only 3400 - $4500 \mathrm{MW}$ after preliminary calculation. Therefore all the Qinghai's PV power could not be consumed by Qinghai grid itself. Besides, the surrounding provinces such as Gansu and Xinjiang are also met with difficulty of RE consumption, hardly helping Qinghai to accommodate extra PV generation.

\subsubsection{Insufficient Flexibility of Conventional Generation Units}

The PV power output is extremely high in the mid-day of Qinghai. At that time, the demand is sometimes not as much as generated power. In addition, more than $60 \%$ of the thermal units must supply heat in the heating period and the regulation capability of conventional thermal units is quite inflexible during the heating period.

Moreover, the system flexibility will decrease when hydro power usually run at its maximum output in the flood season of summer, the acceptable PV power will be reduced further at that time.

\subsubsection{Transmission Limitation}

Solar energy is useful only when the PV power can be transmitted from the PV panel to the terminal loads via the power grid. However, with the rapid development of RE, an appropriate construction plan for both renewable plants and transmission facilities has been lacking. The construction period of RE plants is much shorter than that of transmission lines. Besides, unlike the distributed integration of E.U., renewable plants in Qinghai are often located at remote areas where the resource is perfect but the demand is low; thus, the transmission capability shows a significant impact on RE operation.

In the PV power base of Haixi district of Qinghai, PV stations are integrated intensively, and local transmission capacity is obviously insufficient, transmission system operates at its stability limitation all the time, and some substations 
also meet its capacity limitation. Once the weather is good enough, the output of PV stations could not be fully transmitted to the load center due to transmission limitation.

\section{50 MW PV Power Station with 15 mw/18 MWH Energy Storage}

The mentioned PV-storage demonstration power station locates east of Ge'ermu city in Qinghai province with the altitude of 2900 metres.

\subsection{PV Power Station and Energy Storage System}

In this demonstration project, the installed capacity of PV power station is 53.54 $\mathrm{MWp}$, and all equipped with $310 \mathrm{Wp}$ polycrystalline silicon modules. Finally the PV station has 50 normal centralized 1MWp panels and a \pm 12.5 Mvar SVC.

The total energy capacity of the energy storage system is $15 \mathrm{MW} \times 1.2 \mathrm{~h}(18$ MWh), including 6 of $3 \mathrm{MW}$ lithium iron phosphate battery units.

\subsection{Implement of Energy Storage System in Promoting RE Operation and Control}

For PV-storage coordinated generation system, the most implemented technology is electrochemical energy storage which has advantages of high density, small size and fast regulation capability.

Depend on different capacity and energy volume, the energy storage system could be used in different ways to help RE operation and control, such as improving RE regulation capability, peak load shifting, increasing RE power reliability, smoothing RE output and so on. And all this functions are needed to allocate suitable energy volume and reasonable dispatching and control strategy.

The energy storage system with large capacity and volume is available to store unstable RE generation when it has to be curtailed and then discharge stably while getting command from system operator. Thus RE becomes dispatchable power source. Figure 4 below shows how a roof PV system shifting its peak power via energy storage system. At high PV output time, the load is usually low and the extra electricity is collected by energy storage system. When the PV system could not generate power at night peak load time, the storage system will discharge to meet some demand.

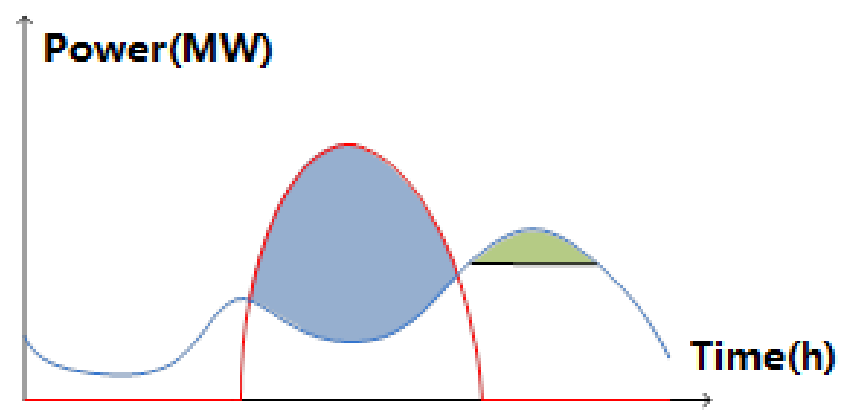

Figure 4. Peak load shift via energy storage. 


\section{Modeling and Method}

Currently the system operators of Qinghai grid are more relying on the plan to maintain supply reliability. Therefore, an optimal dispatching strategy between PV and energy storage system is needed to help the system operator to manage renewable generation, especially in the situation of PV curtailment.

\subsection{PV Generation}

The modeling of PV output in time series is as follows: 1) Transfer PV output to a relative stable output curve based on clear sky model; 2) Weather type classification and modification; 3) Parameter fitting and probability statistics; 4) Random sampling and recovering simulation output series with clear sky model; 5) Effectiveness validation.

\subsubsection{PV Relative Output Based on Clear Sky Model}

For every moment of daytime, the PV output $P(i, t)$ can be transferred by comparing with theoretical output under clear sky situation, and PV relative output $P_{N}(i, t)$ is obtained:

$$
P_{N}(i, t)=\frac{P(i, t)}{P_{D C I}(i, t)}
$$

where $P_{D C I}(i, t)$ indicates the clear sky theoretical output at time $t$ of day $i$. Then we resolve $P_{N}(i, t)$, it can be described as the sum of base power and uncertain power:

$$
\begin{gathered}
P_{N}(i, t)=P_{S}(i)+\Delta P_{N}(i, t) \\
P_{S}(i)=\frac{1}{n} \sum_{t=1}^{n} P_{N}(i, t)
\end{gathered}
$$

where $\Delta P_{N}(i, t)$ indicates variation factor that caused by different weather situation at time t of day $i . \quad P_{S}(i)$ is the base power of day $i$.

Put equation (2) into (1) then we have:

$$
P(i, t)=P_{D C I}(i, t) \cdot\left(P_{S}(i)+\Delta P_{N}(i, t)\right)
$$

Equation (4) is the complete model of PV power output. Figure 5 gives the complete model profile of PV station someday. Additionally, (b) of Figure 5 is PV relative output of that day; and from (c) it is seen that the relative output can be transfer to the sum of base power and variation factor.

\subsubsection{Weather Type Classification}

In this paper, the historical output of PV station and locational meteorological data are counted. The daily output can be simply classified to 4 typical weathers, clear, cloudy, overcast and changing weather. The changing weather mentioned here indicate such as overcast changing to cloudy, overcast changing to rainy, rainy changing to clear and so on. It is obvious that PV output are significant different under different weather types, and the electricity production and power variation are also have quite differences. Then the actual meaning of weather type classification is to classify PV power curves of different days. 


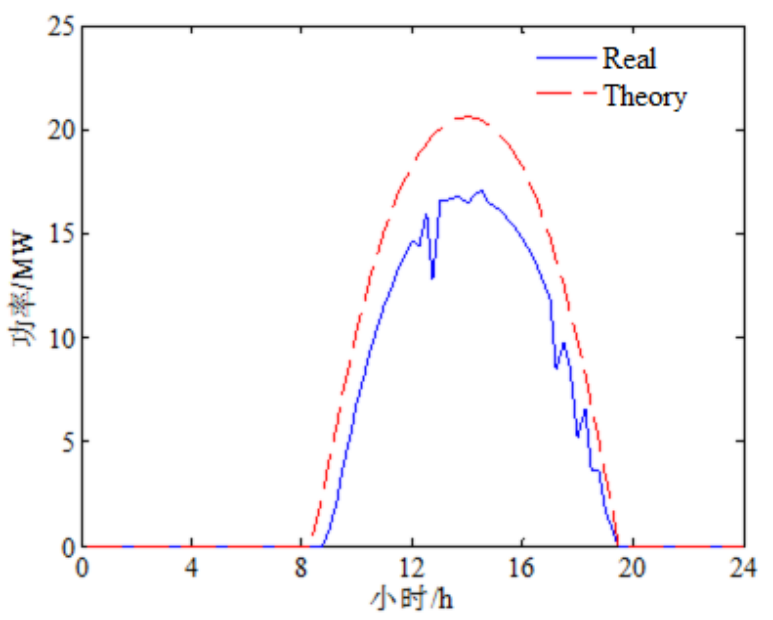

(a)

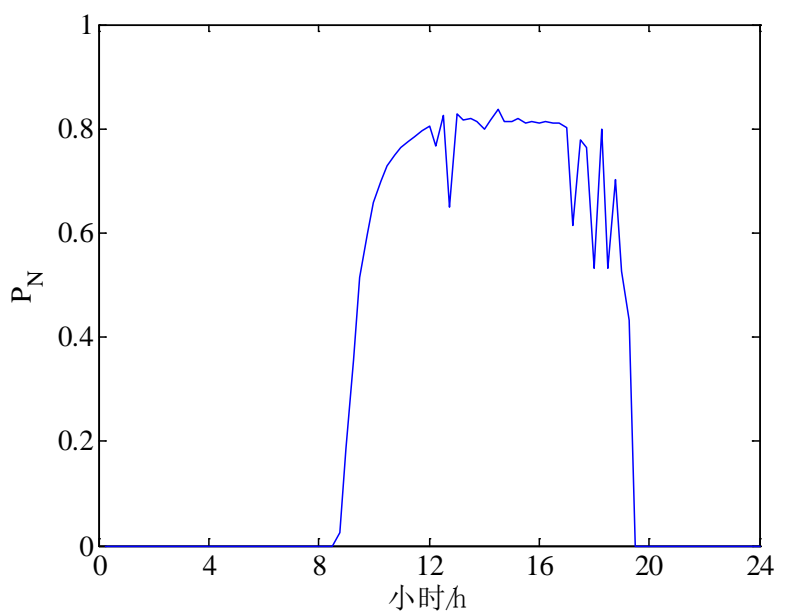

(b)

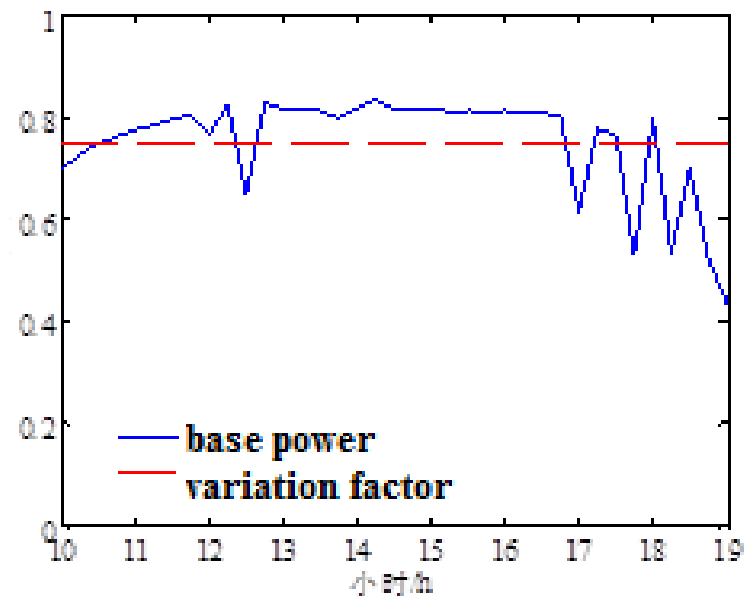

(c)

Figure 5. PV power output model. (a) Clear sky output and real output. (b) Relative output. (c) Base power and variation factor.

\subsubsection{Parametres Fitting and Statistics}

The per unit value of all kinds of weather types is nearly following normal dis- 
tribution. For a better accuracy, to implement three-component mixed Gaussian probability distribution, and the function is as follows. The distribution parametres can be based on maximum likelihood estimation (MLE) of expectation maximization (EM), therefore the probability distribution function is obtained.

$$
\begin{aligned}
f(x)= & \alpha_{1} \frac{1}{\sqrt{2 \pi \sigma_{1}}} e^{\frac{1}{2 \sigma_{1}^{2}}\left(x-\mu_{1}\right)^{2}}+\alpha_{2} \frac{1}{\sqrt{2 \pi \sigma_{2}}} e^{\frac{1}{2 \sigma_{2}^{2}}\left(x-\mu_{2}\right)^{2}} \\
& +\alpha_{3} \frac{1}{\sqrt{2 \pi \sigma_{3}}} e^{\frac{1}{2 \sigma_{3}^{2}}\left(x-\mu_{3}\right)^{2}}
\end{aligned}
$$

\subsubsection{Simulation of Time-Series PV Output}

After statistics we have probability feature of time-series PV output, then it is available to simulate time-series PV output by sequential sampling. The relative PV output thus can be calculated by relative output model, in addition, the relative output at sunrise and sunset time of clear day should be modified. In the end, the simulation time series PV output is recovered via clear sky model.

\subsubsection{Modelling Process}

To sum up above, the time-series PV output modelling process is as Figure 6 bellow.

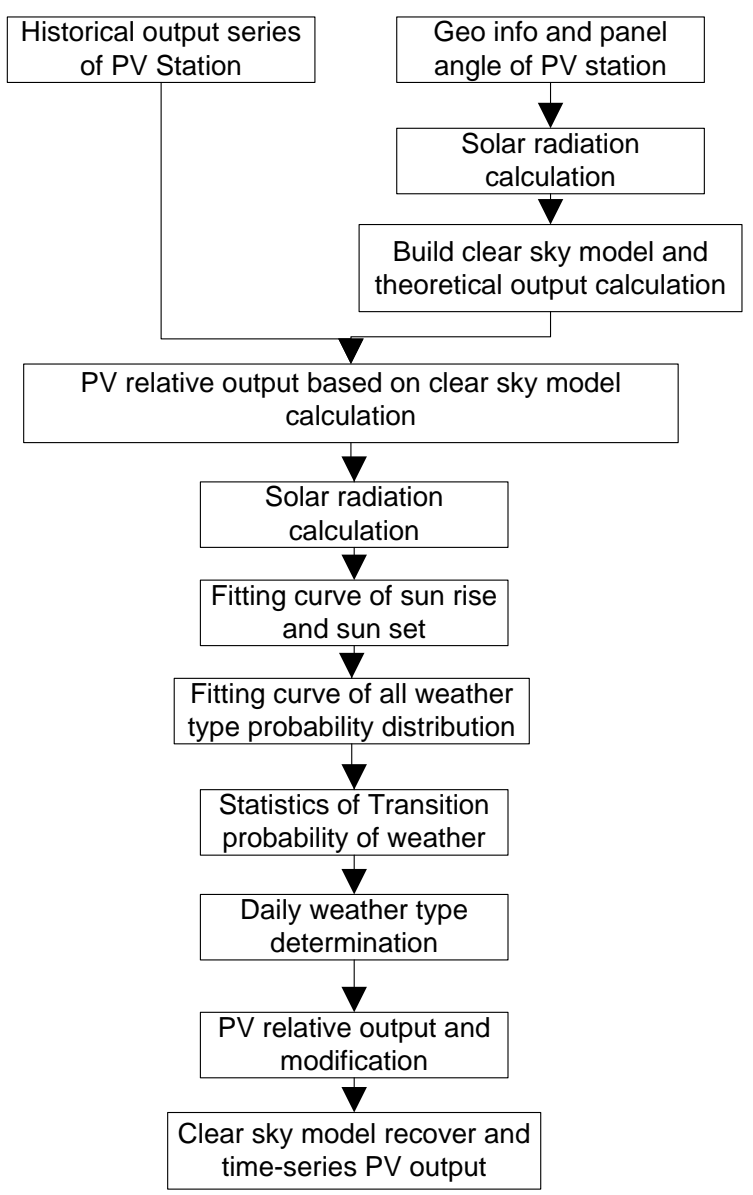

Figure 6. The time-series PV output modelling process. 


\subsection{Energy Storage System}

Energy storage device (system) include electricity storage and heat storage, and its operation characteristics is presented in Figure 7 and function (6).

$$
\left\{\begin{array}{lr}
S_{i, t+1}^{\text {level }}=S_{i, t}^{\text {level }}+P_{i, t}^{\text {stoload }}-P_{i, t}^{\text {sto }} / L_{i}^{\text {sto }} & \forall i \in I_{\text {elecsto }} ; t \in T \\
S_{i, t}^{\text {level }} \leq S_{i, t}^{\text {sto }} & \forall i \in I_{\text {elecsto }} ; t \in T \\
P_{i, t}^{\text {stoload }} \leq S_{i, t}^{L} & \forall i \in I_{\text {elecsto }} ; t \in T
\end{array}\right.
$$

where the first equation indicates the energy storage level of energy storage system at the time of $t+1 . L_{i}^{\text {sto }}$ indicates the energy loss rate. The second inequation represents the energy storage level of energy storage system at the time $t$ $S_{i, t}^{\text {level }}$ is smaller or equal to the total energy capacity $S_{i, t}^{\text {sto }}$. The third inequation represents the output power of energy storage system $P_{i, t}^{\text {stoload }}$ that should smaller or equal to total capacity of energy storage system $S_{i, t}^{L}$.

The battery storage mentioned in this paper is electricity storage, and its basic operation feature and limitation are as follows:

1) Charging and discharging limit

$$
\begin{aligned}
& 0 \leq C X_{a}^{t}+C X_{b}^{t} \leq 1 \\
& C X_{b}^{t} \times P_{c x g \min }^{t} \leq P_{c x g}^{t} \leq C X_{b}^{t} \times P_{c x g \max }^{t} \\
& 0 \leq P_{c x p}^{t} \leq C X_{a}^{t} \times N_{c x \max }^{t} \times P_{c x p u n i t}^{t}
\end{aligned}
$$

2) Energy storage capacity limit

$$
W_{0}^{t}-W_{\max } \leq P_{c x g}^{t} / \eta-P_{c x p}^{t} \leq W_{0}^{t}-W_{\min }
$$

where $W_{0}$ indicates initial electricity of energy storage system; $W_{\min }$ indicates minimum stored electricity; $W_{\max }$ indicates maximum stored electricity; $\eta$ indicates energy transfer efficiency.

3) Electricity balance

$$
\begin{aligned}
& P_{c x g}^{t} / \eta-P_{c x p}^{t}=W_{0}^{t}-W_{\text {end }}^{t} \\
& W_{0}^{t}=W_{\text {end }}^{t-1} \\
& W_{0}^{1}=W_{\text {InitialCap }}
\end{aligned}
$$

where $W_{\text {end }}$ indicates ultimate electricity of energy storage system.

4) Power output limit

$$
P_{c x g \min }^{t} \times\left(1-W_{a b}^{t}\right) \leq P_{c x g}^{t} \leq P_{c x g \max }^{t} \times\left(1-W_{a b}^{t}\right)
$$

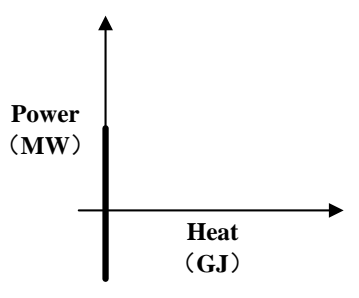

(a)

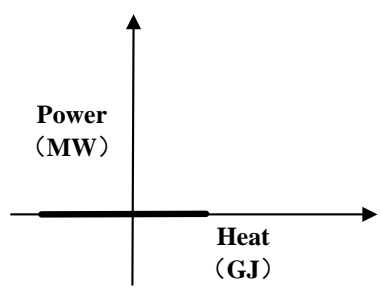

(b)

Figure 7. Characteristics of electricity storage and heat storage. (a) Electricity storage. (b) heat storage. 
where $W_{a b}=1$, while PV curtailment occur, and the power output of energy storage system is 0 .

5) Discharging limit

$$
\begin{gathered}
P_{c x p}^{t}=N_{c x}^{t} \times P_{c x p u n i t}^{t} \\
0 \leq N_{c x}^{t} \leq N_{c x \max }^{t} \\
N_{c x \max }^{t}=\frac{P_{c x p \max }^{t}}{P_{c x p u n i t}^{t}}
\end{gathered}
$$

\subsection{Power System Time-Series Production Simulation}

The power system production simulation is the method of simulating power balance and all generation units' operational status under certain system load situation. In this paper, the time-series production simulation is implemented. Considering load curve vary with time, simulate actual power system balance process with one hour resolution and its basic functional description can be seen in Figure 8.

Because of continuity of every time resolution and simulation step is determined, some power system operation limitations must be satisfied. For example, ramping limitation of units, minimum output of thermal unit, system reserve and transmission limit.

\section{Validation and Analysis}

The effectiveness of the proposed dispatching strategy is evaluated by using the time-series production simulation. The simulation is carried out with the actual operation data of the Qinghai power grid.

\subsection{PV-Energy Storage System Coordinated Dispatching}

The key point of minimizing RE generation curtailment is reasonable RE power plan in a non-market power system. Because of energy storage system, the power

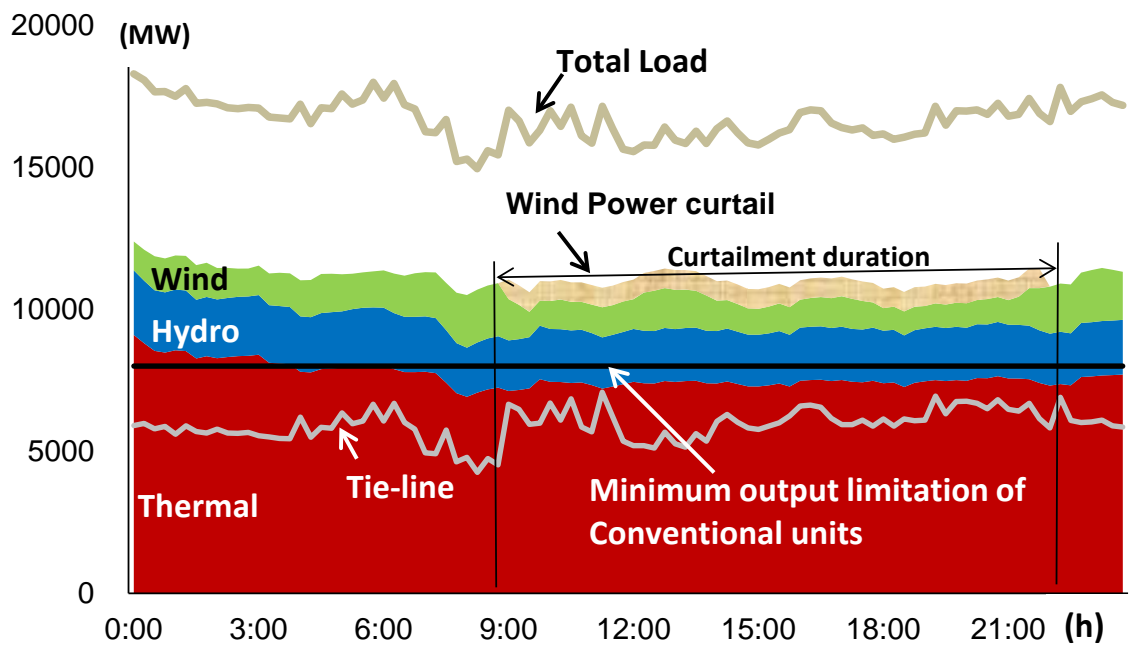

Figure 8. Profile of power system time-series production simulation. 
prediction of PV station is more accuracy than other normal stations, even the day ahead forecasting error could be less than $5 \%$. Therefore, the system operators should fully consider the advantages of PV-storage system such as high accuracy and ability of upward regulation, and schedule the power plan as much as possible under the prediction value.

In addition, when PV curtailment could not be avoid due to the system limitation, the power plan of PV-storage station is assumed to be extended for a certain time after sunset of that day, so that evening peak load can be covered by PV power to a certain degree. The extra planned electricity should be less or equal $18 \mathrm{MWh}$ which is the total volume of energy storage system. The proposed scheduling strategy is described in Figure 9.

\subsection{Solar Power Station Coordinated Operation with Heat Storage}

If the electricity of solar power station is stored in terms of heat, that is what we called concentrating solar power (CSP) station with heat storage system. The power characteristics of PV station, CSP and CSP with heat storage are of certain difference. Figure 10 shows power curves of 200 MW PV power station, CSP

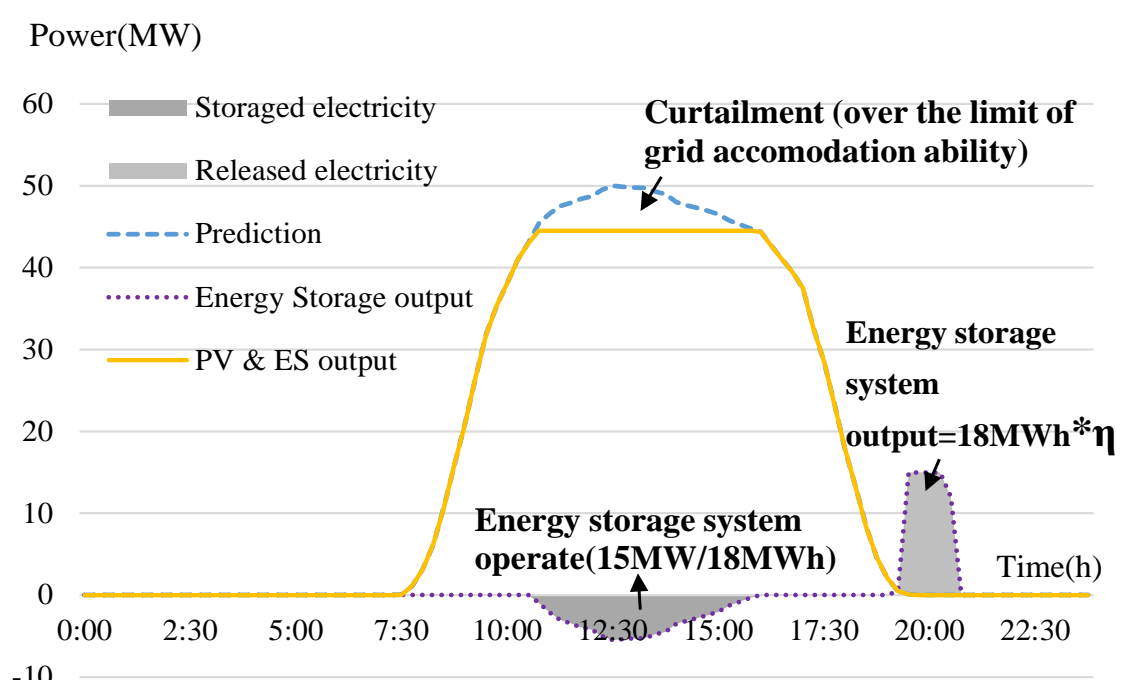

Figure 9. Day ahead PV-energy storage coordinated dispatching.

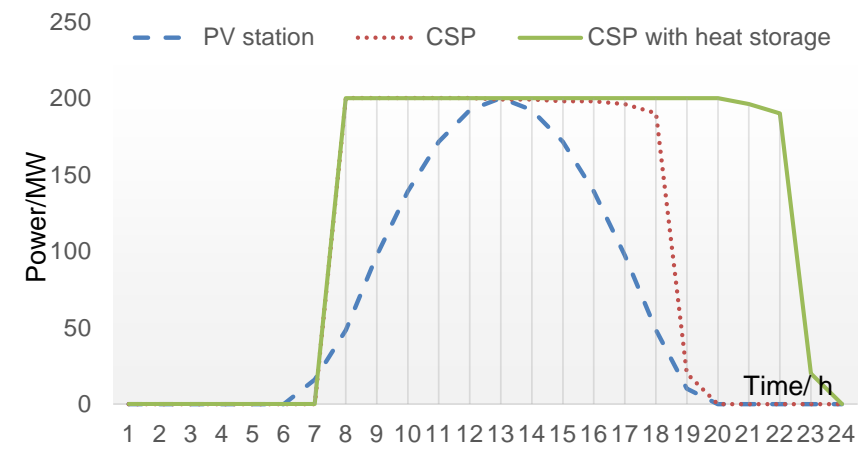

Figure 10. Power curves of 3 different types of $200 \mathrm{MW}$ solar power station. 
station and CSP with 4 hour heat storage under clear day, respectively. It is obvious that the PV power station and CSP station without storage have similar power curves.

For another comparison with same electricity of these three types of solar power stations, the maximum output is modified to produce same energy volume. As shown in Figure 11, in a sunny day of summer, the $2970 \mathrm{MWh}$ electricity could be the production of 200 MW CSP with 4 hour heat storage, 275 MW CSP or 360 MW PV station, respectively. It is clear that for a same energy production, the PV station and CSP without heat storage should increase its capacity (or maximum output).

\subsection{Large-Scale PV Generation Coordinated Operation with Pump Storage}

In the development plan of Qinghai province, the expected installed capacity of all power sources in 2020 are listed in Table 1. The 2020 scenario is analyzed based on time-series production simulation.

After whole year simulation analysis of Qinghai grid, the curtailment of PV generation was $3.7 \%$ of total theoretical PV generation in 2015. As same compu-

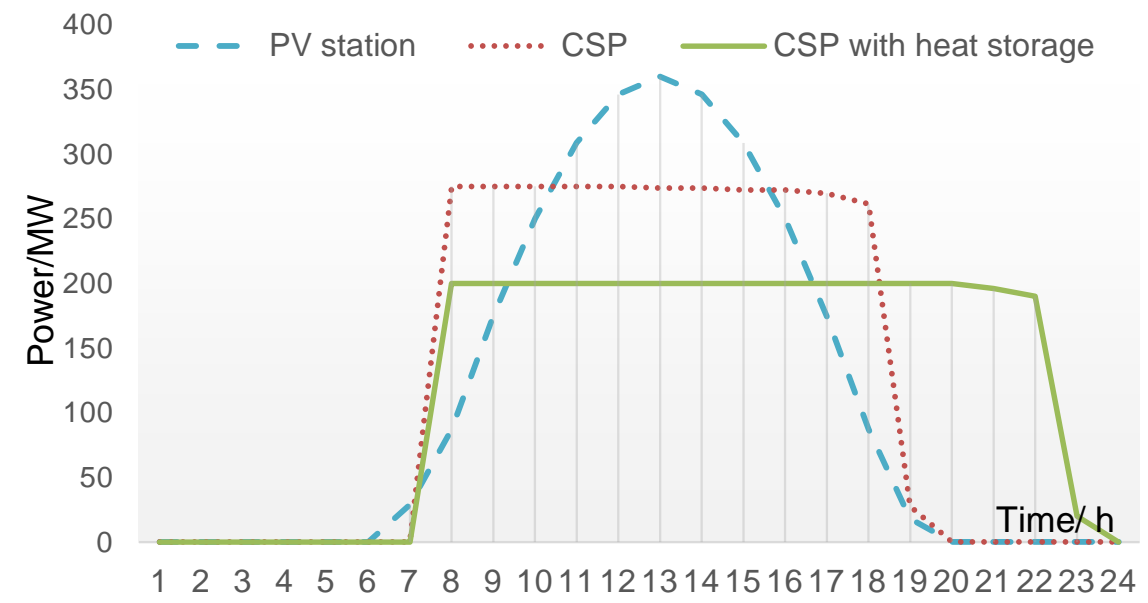

Figure 11. Power curves of 3 different types of solar power station with same electricity production.

Table 1. The power sources and load level of 2020 scenario.

\begin{tabular}{cc}
\hline Capacity/Load & Planned value \\
\hline Coal fired power (MW) & 8480 \\
Hydro power (MW) & 13,070 \\
Wind power (MW) & 3000 \\
PV power (MW) & 10,144 \\
Electricity demand (TWh) & 102.5 \\
Maximum load (MW) & 14,440 \\
Increasing rate of demand (\%) & 10 \\
\hline
\end{tabular}


tational conditions as 2015 scenario, according to the development plan of 2020 of Qinghai province, the simulated PV generation in 2020 will reach 6.47 TWh and curtailed PV electricity was 10.5 TWh, and $61.95 \%$ of PV was curtailed. Therefore it will be significantly tough for PV consumption in Qinghai grid if under 2020 development plan. To solve this, we consider to implement largescale energy storage system to reduce PV curtailment and the pumped storage station may one of the best choices from the economical perspective.

Again the simulation of coordinated operation of planned $10 \mathrm{GW}$ PV with pumped storage stations was conducted according proposed dispatching strategy. Under the same computational conditions with 2020 scenario, the result listed in Table 2 shows that the curtailment rate of PV generation can be decreased to around 5\% while $1200 \mathrm{MW}$ pumped storage station are installed to co-operation with RE, and the full load hour (FLH) of pumped storage station is $1313 \mathrm{~h}$. Appropriate energy storage system coordinated operate with large-scale $\mathrm{RE}$ will be a feasible solution for the future high penetration RE power system operation.

\section{Conclusion}

The current status of solar PV power operation in Qinghai grid was introduced and bottlenecks of RE development and operation were discussed in this paper. A PV-energy storage coordinated optimal operation strategy under non-market situation was presented. Considering the flexibility of energy storage system, the total output of all generating units will be easier to follow the power plan command from system operators; therefore, the impact of renewable's variability on the system could be significantly reduced, and PV curtailment thus decrease accordingly. The effectiveness of the proposed strategy and method is validated by the time-series production simulation of the Qinghai power grid. Furthermore, solar power with heat storage and large-scale PV operation with pumped storage in 2020 scenario are also analyzed. The results indicate that the appropriate energy storage system could help to decrease PV power curtailment effectively under a coordinated optimal dispatching and control strategy.

Table 2. The comparison of PV operation with and without energy storage in 2020 scenario of Qinghai grid.

\begin{tabular}{ccc}
\hline $\begin{array}{c}\text { Qinghai grid } \\
2020 \text { scenario }\end{array}$ & $\begin{array}{c}\text { Without } \\
\text { Energy storage }\end{array}$ & $\begin{array}{c}\text { With 1200 MW pumped } \\
\text { storage }\end{array}$ \\
\cline { 2 - 3 } PV generation & TWh & TWh \\
Curtailment & 6.47 & 16.12 \\
Curtailment rate (\%) & 10.5 & 5 \\
FLH of pumped storage \\
system (hour)
\end{tabular}




\section{Acknowledgements}

This work was supported by the Science and Technology Project of SGCC, Science and Technology Project of Qinghai Power Grid Corporation and the PV Power Integration Technology Key Lab of Qinghai Province (2014-Z-Y34A).

\section{References}

[1] Fang, C., Xia, Q. and Sun, X.(2010) Generation Maintenance Scheduling with Significant Wind Power Penetration, Automation of Electric Power Systems,19, 20-25.

[2] Bouffard, F.and Galiana, F.D.(2008) Stochastic Security for Operations Planning with Significant Wind Power Generation, IEEE Transactionson Power Systems, 23, 306-316.https://doi.org/10.1109/TPWRS.2008.919318

[3] Shuo, M. Xiaofei, L. and Yanping, X. (2016)Multi-source generation Optimal Dispatching Strategy with Significant Renewable Energy Penetration Under Non-Market Condition, Advances in Power And Energy Engineering, APPEEC 2016, 557-563.

[4] Li., Z., Han, X.S., and Yang, M.(2010) Power System Dispatch Considering Wind Power Grid Integration, Automation of Electric Power Systems,34, 15-19.

[5] Barth, R,. Brand, H. and Meibom, P. (2006) A Stochastic Unit Commitment Model for the Evaluation of the Impacts of the Integration of Large Amounts of Wind Power, Proceedings of 9th International. ConferenceProbabilisticMethods Applied to Power Systems. Stockholm: Sweden. https://doi.org/10.1109/pmaps.2006.360195

[6] Denholm, P. Ela, E., Kirby, B.and Milligan, M. (2010) The Role of Energy Storage with Renewable Electricity Generation. Report of National Renewable Energy Laboratory. Colorado, USA.https://doi.org/10.2172/972169

[7] Mears, L., Gotschall, H., Key, T.and Kamath, H. (2004) EPRI-DOE Handbook Supplement ofEnergy Storage for Grid ConnectedWind Generation Applications. Report of Electric Power Research Institute. California \& Washington, D.C: USA.

[8] Zhang, Z., Sun, Y., Li, G., Cheng, L. and Lin, J. (2011) A Solution of Economic Dispatch Problem Considering Wind Power Uncertainty. Automation of Electric Power Systems,22, 125-131.

[9] Zhang, G., Zhang, B. and Wu, W.C.(2011) Coordinated Roll Generation Scheduling Considering Wind Power Integration. Automation of Electric Power Systems,19, 18-23.

[10] Fink, S., and Mudd, C.(2012) Wind Energy Curtailment Case Studies. Report of National Renewable Energy Laboratory. Washington, D.C: USA.

[11] Wang, Q.K.(2012) Update and Empirical Analysis of Domestic and Foreign Wind Energy Curtailment. East China Electric Power, 3, 78-82. 
Submit or recommend next manuscript to SCIRP and we will provide best service for you:

Accepting pre-submission inquiries through Email, Facebook, LinkedIn, Twitter, etc. A wide selection of journals (inclusive of 9 subjects, more than 200 journals)

Providing 24-hour high-quality service

User-friendly online submission system

Fair and swift peer-review system

Efficient typesetting and proofreading procedure

Display of the result of downloads and visits, as well as the number of cited articles Maximum dissemination of your research work

Submit your manuscript at: http://papersubmission.scirp.org/

Or contact epe@scirp.org 